\title{
Evaluation of dentin desensitization protocols on the dentinal surface and their effects on the dentin bond interface
}

\author{
Wilfredo Gustavo Escalante-Otárola ${ }^{a}$, Gabriela Mariana Castro-Núñez ${ }^{\mathrm{a}}$, \\ Keren Cristina Fagundes Jordão-Basso ${ }^{\mathrm{a}}$, Bruno Martini Guimarães ${ }^{\mathrm{b}}$, Regina Guenka Palma-Dibb ${ }^{\mathrm{c}}$, \\ Milton Carlos Kuga ${ }^{a, *}$
}

${ }^{a}$ Restorative Dentistry Department, Araraquara Dental School, São Paulo State University (Unesp), 14801-903, Araraquara, São Paulo, Brazil

${ }^{\mathrm{b}}$ Dentistry, Endodontic and Dental Materials Department, Bauru Dental School, São Paulo University, 17012-901, Bauru, São Paulo, Brazil

${ }^{\mathrm{c}}$ Restorative Dentistry Department, Ribeirão Preto Dental School, São Paulo University, 14040-904, Ribeirão Preto, São Paulo, Brazil

\section{A R T I C L E I N F O}

\section{Keywords:}

Dentin hypersensitivity

Desensitizing agents

Dentin adhesive

Hybrid layer

Scanning electron microscopy

Bond strength

\begin{abstract}
A B S T R A C T
Objectives: To evaluate the effect of desensitizing agent containing calcium phosphate nanoparticles on the bond strength of etch-and-rinse adhesive system (Scotchbond Multi-Purpose), presence of precipitate, dentinal tubule obliteration and hybrid layer formation in dentin in comparison with potassium nitrate plus sodium fluoride or strontium chloride compounds.

Methods: 150 bovine incisors were treated with $(\mathrm{n}=10)$ : G1, Desensibilize Nano $\mathrm{P}\left(\mathrm{Ca}_{3}\left(\mathrm{PO}_{4}\right)_{2}+5 \%\right.$ $\left.\mathrm{KNO}_{3}+0.9 \% \mathrm{NaF}\right)$; G2, Desensibilize $\left(10 \% \mathrm{SrCl}_{2}+5 \% \mathrm{KNO}_{3}\right) ; \mathrm{G} 3$, Desensibilize $\mathrm{KF} 2 \%\left(5 \% \mathrm{KNO}_{3}+0.2 \% \mathrm{NaF}\right) ; \mathrm{G} 4$, Ultra $\mathrm{EZ}\left(3 \% \mathrm{KNO}_{3}+0.25 \% \mathrm{NaF}\right)$ and $\mathrm{G} 5$, no treated (control). Scanning electron microscopy was used to assess the incidence of precipitates $(500 \times)$ and obliterated dentinal tubule counts $(1.000 \times)$. The adhesive system was used after all desensitization treatments. The bond strength $(n=40)$ and the fracture pattern were evaluated. Confocal laser microscopy was used to quantify the hybrid layer formation in dentin.

Results: G1 and G2 presented higher adhesive system bond strength (MPa) than G4 and G5, however no significant differences were observed in comparison with G3. Cohesive fracture was frequently found: G1 (58.5\%), G2 (51.3\%) and G3 (43.8\%). G1 showed the highest incidence of precipitates and the highest number of blocked dentinal tubules. G1 and G2 presented similar hybrid layer formation and the highest hybrid layer formation values.

Conclusions: Desensibilize Nano P (G1) favored the bond strength of the adhesive system to dentin, increased the precipitation of residues, obliteration of dentinal tubules, and hybrid layer formation in comparison with other agents.

Clinical relevance: Desensitizers promote dentin obliteration, however, may affect dentin bonding.
\end{abstract}

\section{Introduction}

Dentin hypersensitivity (DH) is pain resulting from dentin exposure in response to chemical, thermal, tactile or osmotic stimuli and cannot be considered a pathology or any other defect. This pain does not occur spontaneously and disappears after the stimulus is removed [1-3].

DH affects a large part of the population in all ethnic groups. A study on Dentin Hypersensitivity conducted by the Canadian Advisory Board reported a prevalence ranging from 8 to $57 \%$ in adults between 20 and 40 years old [1]. However, the treatments are not effective and definitive.

Cervical root dentin exposure and presence of open dentinal tubules are two fundamental conditions for DH development [4-6]. Thus, therapeutic procedures for $\mathrm{DH}$ are based on substances that depress neural transmission, and also, they may be associated with obliteration of exposed dentinal tubules $[7,8]$.

Several DH protocols mainly containing potassium nitrate associated with sodium fluoride and / or strontium chloride have been proposed, however showing disappointing clinical results $[9,10]$. On the other hand, calcium phosphate nanoparticles associated with potassium nitrate and sodium fluoride (Desensibilize Nano P) provide calcium and fluoride ions deposition on dentin surface, favoring dentinal tubules obliteration [11]. However, many cases require an adhesive restoration after desensitization protocol, and the effects of DH treatments on the bond strength of etch-and-rinse adhesive systems to dentin, and on the hybrid layer formation are still unclear.

\footnotetext{
* Corresponding author

E-mail address: kuga@foarunesp.br (M.C. Kuga).
} 
Therefore, the aim of this study was to evaluate the effect of a desensitizing agent containing calcium phosphate nanoparticle (Desensibilize Nanop) on the bond strength of etch-and-rinse adhesive system (Scotchbond Multi-Purpose), the presence of precipitate, dentinal tubule obliteration and hybrid layer formation in dentin in comparison with potassium nitrate with sodium fluoride (Ultra EZ and Desensibilize KF 2\%) and / or strontium chloride (Desensibilize) compounds. The null hypothesis was that desensitizing agents would have no effect on the parameters analyzed.

\section{Materials and methods}

This present study was approved by the Ethics Committee of Araraquara Dental School, São Paulo State University (Proc. CEUA no 2/2015). A hundred and fifty bovine incisors with similar crowns and root anatomies were stored in $0.1 \%$ thymol solution at $4{ }^{\circ} \mathrm{C}$ until the research began.

Fragments $(10 \mathrm{~mm}$ long $\times 10 \mathrm{~mm}$ wide $\times 5 \mathrm{~mm}$ thick) were obtained from the middle third of the tooth by using a hard tissue cutting machine (Isomet 100, Buehler, Lake Bluff, IL) cooled under running water. The buccal surfaces of fragments were flattened with a polishing machine (DP-10; Panambra, Struers, Ballerup, DI) using \#600 sandpaper for $20 \mathrm{~s}$ (ISO 6344-1), to expose the dentin, and planing to standardize the smear layer. The dentin surface was previously treated by using $17 \%$ EDTA (Biodinâmica, Ibiporã, PR, Brazil) for 3 min to simulate an exposed and sensitive dentin model $[9,10]$. Afterwards, the specimens were rinsed with distilled water and stored in artificial saliva until they were used.

\subsection{Application of dentin desensitization protocols}

Four protocols using dentin desensitizer agents were used in this study. The specimens were randomly divided into four groups (G1 to G4) and a control (G5) as described in Table $1(\mathrm{n}=10)$. All desensitization protocols were performed in accordance with the respective manufacturer's instructions. In G1, the desensitizer agent was rubbed on the dentin surface with a rubber cup for $10 \mathrm{~s}$ and left undisturbed for 5 min during every session. All groups were submitted to 4 treatment sessions at 1week intervals [12]. Between each session, the teeth were stored in artificial saliva $\left(0.375 \mathrm{~g} / \mathrm{l} \mathrm{CaCl}_{2} \cdot 2 \mathrm{H}_{2} \mathrm{O}, 0.125 \mathrm{~g} / 1 \mathrm{MgCl}_{2} \cdot 6 \mathrm{H}_{2} \mathrm{O}\right.$, $1.2 \mathrm{~g} / 1 \mathrm{KCl}, 0.85 \mathrm{~g} / 1 \mathrm{NaCl}, 2.5 \mathrm{~g} / 1 \mathrm{NaHPO}_{4} .12 \mathrm{H}_{2} \mathrm{O}, 1 \mathrm{~g} / 1$ sorbic acid, $5 \mathrm{~g} / 1$ hydroxyethyl cellulose-sodium, and $43 \mathrm{~g} / 1$ sorbitol solution) (Arte \& Ciência, Araraquara, São Paulo, Brazil), at $37^{\circ} \mathrm{C}$. The artificial saliva was replaced in every session. G5 (negative control) received no treatment and was kept in artificial saliva.

\subsection{Evaluation of residue precipitation and dentinal tubule occlusion}

Fifty specimens were randomly divided into experimental groups and control $(\mathrm{n}=10)$. After the desensitization protocols, the specimens were kept in artificial saliva for $24 \mathrm{~h}$. The specimens were dried inside a closed chamber containing colloidal silica for 7 days. Then the specimens were mounted onto metal stubs, gold-sputter coated (single cycle-

Table 1

Composition of dentin desensitizing agents.

\begin{tabular}{lll}
\hline Group & Composition & Manufacturer \\
\hline G1 - Desensibilize NanoP & $\mathrm{Ca}_{3}\left(\mathrm{PO}_{4}\right)_{2}(\mathrm{~nm})+\mathrm{KNO}_{3}(5 \%)+$ & FGM, Brazil \\
& $\mathrm{NaF}(0.9 \%)$ & \\
G2 - Desensibilize & $\mathrm{SrCl}_{2}(10 \%)+\mathrm{KNO}_{3}(5 \%)$ & FGM, Brazil \\
G3 - Desensibilize $\mathrm{KF} 2 \%$ & $\left.\mathrm{KNO}_{3}(5 \%)+\mathrm{NaF}^{2} \%\right)$ & FGM, Brazil \\
G4 - Ultra EZ & $\mathrm{KNO}_{3}(3 \%)+\mathrm{NaF}(0.25 \%)$ & Ultradent, USA \\
G5 - Negative Control & - & - \\
\hline
\end{tabular}

$\mathrm{Ca}_{3}\left(\mathrm{PO}_{4}\right)_{2}(\mathrm{~nm})$, calcium phosphate nanoparticles; $\mathrm{KNO}_{3}$, potassium nitrate; $\mathrm{NaF}$, sodium fluoride; $\mathrm{SrCl}_{2}$, Strontium chloride.
$120 \mathrm{~s}$ ) under vacuum, in a metalizing chamber (MED 010, Balzers Union, Balzers, Liechtenstein) and examined by means of scanning electron microscopy with JEOL 6060 (JEOL 6060; JEOL Ltda, Tokyo, Japan) operating at $20 \mathrm{kV}$. Four different fields were initially assessed and the most representative image was obtained at $500 \times$ magnification.

Another image at $1000 \times$ magnification was obtained from this same site to count the unblocked and open dentinal tubules. All images were obtained by only one operator. Another two calibrated examiners classified the presence of residues according to Kuga et al. [13]. Two different examiners counted the open dentinal tubules in each image of the specimens. The results obtained by the two examiners were used to calculate the mean value that was determined for the specimen.

\subsection{Energy-dispersive $X$-ray analysis (EDX)}

Four specimens of each group were analyzed using scanning electron microscopy (SEM) and submitted to carbon coverage (BalTec SCD 004 Sputter Coater; Balzers,Vaduz, LI), at $15 \mathrm{kV}$ for $180 \mathrm{~s}$. Afterwards, dentin surface was submitted to SEM and EDX (JEOL 6060; JEOL Ltda, Tokyo, Japan) to assess the precipitate formation.

\subsection{Bonding procedure}

After the treatment protocols, one hundred specimens were randomly divided: fifty were subjected to testing to evaluate the bond strength of the adhesive system to cervical dentin; and fifty to access the hybrid layer formation. Acid etching was performed with 37\% phosphoric acid (Condac 37; FGM, Joinville, Brazil), for $15 \mathrm{~s}$ and rinsed with distilled water for $30 \mathrm{~s}$. The surface was slightly dried using air spray and the etch-and-rinse adhesive system (Scotchbond Multi-Purpose; $3 \mathrm{M}$ ESPE, St. Paul, MN, USA) was immediately applied according to manufacturer's instructions. The adhesive system was light polymerized by using a LED system (LED Bluephase; Ivoclar Vivadent, Schan, Liechtenstein, AL), with an intensity of $1200 \mathrm{~mW} / \mathrm{cm}^{2}$ for $10 \mathrm{~s}$.

\subsection{Bond strength evaluation}

After all treatment protocols, four cylinders made of composite resin specimens were prepared on the buccal surface, two in the mesial and two in the distal region $(n=40)$. A transparent Tygon tube matrix (Tygon tube, R-3603; Saint-Gobain Performance Plastics, Miami Lakes, FL, USA) with an internal diameter of $0.7 \mathrm{~mm}$, and $1.0 \mathrm{~mm}$ high was used for the composite resin filling (Filtek Z-250; $3 \mathrm{M}$, St. Paul, MN, USA) and light polymerized for $40 \mathrm{~s}$.

After preparation, the specimens were stored in a $100 \%$ relative humidity environment at $37^{\circ} \mathrm{C}$ and the shear bond test was performed after $24 \mathrm{~h}$. All fragments were fixed in a metal matrix so that the composite cylinder specimens were placed perpendicularly to a load cell of $0.5 \mathrm{~N}$. An orthodontic wire $(0.2 \mathrm{~mm}$ in diameter) held the composite cylinder base. All specimens were subjected to compressive loading at a crosshead speed of $0.5 \mathrm{~mm} / \mathrm{min}$ in an EMIC DL2000 electromechanical testing machine (EMIC, São José dos Pinhais, PR, Brazil) until the displacement of the composite specimens. The bond strength was obtained from the maximum force $(\mathrm{N})$ divided by the bond area $\left(\mathrm{mm}^{2}\right)$, in MPa. An arithmetic average was calculated for the four composite specimens from each fragment and considered the mean value of the specimens.

\subsection{Fracture mode evaluation}

After the shear bond test, the specimens were dehydrated in colloidal silica for $24 \mathrm{~h}$. The fracture mode was analyzed by using a stereomicroscope (Leica Microsystems, Wetzlar, Germany), at $50 \times$ magnification in order to classify the fracture: $(A D)$ adhesive, when the fracture occurred between the dentin and the adhesive system; (C) 
cohesive, when fracture occurred in the composite resin, and (MI) mixed, when both fracture patterns occurred.

\subsection{Evaluation of hybrid layer formation}

After application of the adhesive system, a $4 \mathrm{~mm}$ high composite resin (Filtek Z-250; 3 M, St. Paul, MN, USA) reconstruction was made on dentin and every $2 \mathrm{~mm}$ thick increment was light polymerized for $40 \mathrm{~s}$ and stored in a $100 \%$ relative humidity. After $24 \mathrm{~h}$, the dental crowns were longitudinally sectioned in the middle third using a hard tissue cutting machine (Isomet; Buehler, Lake Bluff, IL) cooled under running.

The sectioned faces were flattened using \# 600 and then \# 1200 water sandpaper (Norton, Lorena, SP, BR) fitted to a circular polisher (Arotec, Cotia, SP, BR). The specimens were washed with distilled water, the surface was polished using $30 \mu \mathrm{m}$ grain aluminum oxide (Arotec, São Paulo, SP, BR), and a felt disk driven by circular polisher. The specimens were immersed in distilled water and stirred in an ultrasonic tank (Cristófoli, Campo Mourão, PR, USA) for $10 \mathrm{~min}$. Then the specimens were dried using air-spray and the entire surface was etched with 37\% phosphoric acid (Condac 37; FGM Produtos Odontológicos Ltda., Joinville, SC, Brazil) for $20 \mathrm{~s}$. The surfaces were rinsed with distilled water, dehydrated with gentle air-spray and individually fixed on a glass slide in horizontal position. Each specimen was analyzed by means of a laser confocal microscope (LEXT OLS4100; Olympus, Shinjuku-ku, Tokyo, JP) using specific software (Olympus Stream; Olympus, Shinjuku-ku, Tokyo, JP) at $1024 \times$ magnification. The images were saved in TIFF format, the hybrid layer length was measured using the Image $\mathrm{J}$ program, calibrated in micrometers. The hybrid layer length was measured in $100 \mu \mathrm{m}$ sections, with the measurement being performed every $10 \mu \mathrm{m}$, resulting in 10 analyses being obtained for each specimen. The arithmetic average of these measurements represented the mean value of hybrid layer formation in each specimen.

\subsection{Statistical analysis}

Initially all data were submitted to the Shapiro-Wilk test. The bond strength data of the adhesive system evaluated were submitted to ANOVA and Tukey tests. The data of the other evaluations were submitted to the Kruskal Wallis and Dunn tests. All evaluations were performed at a level of $\alpha=5 \%$.

\section{Results}

With regard to the dentin surface evaluation, G1 showed the highest incidence of precipitates compared with the other groups $(P<0.05)$. G2 presented higher amount of precipitates on dentin than G5 $(P<0.05)$. G4, G3 and G2 were similar to each other $(P>0.05)$. Similar results were also observed among G4, G3 and G5 (P > 0.05). Scores were attributed according to the presence of precipitates on dentin surface. Data were submitted to Krukal Wallis and Dunn tests, since the analyzes were carried out using the scores evaluated by examiners. Table 2 shows the median, maximum and minimum values, first and third quartile of scores of precipitates presence.

As regards the number of open dentinal tubules, the highest number of blocked dentinal tubules was observed in G1 $(P<0.05)$. G2 presented a higher number than G4 and G5 $(P<0.05)$, and G2 was similar to G3 $(P>0.05)$. No significant differences were found among G4, G3 and G5 $(P>0.05)$. Results did not show homogeneity of variances, thus, data were not submitted to analysis of variance (ANOVA); then, non-parametric Krukal Wallis and Dunn tests were used in order to avoid the ordinary least square compromising. Those tests are effective to detect diferences in dispersion in identical populations. Table 3 shows the median, maximum and minimum values, first and third quartile of the number of open dentinal tubules. Fig. 1 shows a representative image of the dentin surface after the desensitization
Table 2

Median, maximum and minimum values, first (1Q) and third quartile (3Q) of presence of precipitates on dentin according to the desensitization protocols.

\begin{tabular}{lllll}
\hline GROUP & Median & Maximum & Minimum & $1 \mathrm{Q}-3 \mathrm{Q}$ \\
\hline $\mathrm{G} 1^{\mathrm{a}}$ & 4 & 4 & 4 & $4-4$ \\
$\mathrm{G}^{\mathrm{b}}$ & 3 & 3 & 2 & $2-3$ \\
$\mathrm{G} 3^{\mathrm{bc}}$ & 2 & 2 & 2 & $2-2$ \\
$\mathrm{G}^{\mathrm{bc}}$ & 2 & 2 & 1 & $1-2$ \\
$\mathrm{G5}^{\mathrm{c}}$ & 1 & 1 & 1 & $1-1$ \\
\hline
\end{tabular}

${ }^{\mathrm{ab}}$ Different letters indicate statistically significant difference(?) $\left.(P<0.05)\right)$. G1, Desensibilize Nano P; G2, Desensibilize; G3, Desensibilize KF2\%; G4, Ultra EZ; G5, negative control.

Table 3

Median, maximum and minimum values, first (1Q) and third quartile (3Q) of number of open dentinal tubules (unit) according to the desensitization protocols.

\begin{tabular}{lllll}
\hline GROUP & Median & Maximum & Minimum & $1 \mathrm{Q}-3 \mathrm{Q}$ \\
\hline $\mathrm{G} 1^{\mathrm{a}}$ & 74 & 141 & 21 & $44.5-114.7$ \\
$\mathrm{G}^{\mathrm{b}}$ & 401.5 & 843 & 38 & $216.7-480.0$ \\
$\mathrm{G3}^{\mathrm{bc}}$ & 714.0 & 1151 & 526 & $988.5-646.5$ \\
$\mathrm{G}^{\mathrm{c}}$ & 981.5 & 1175 & 512 & $807.2-1032.7$ \\
$\mathrm{G5}^{\mathrm{c}}$ & 970.0 & 1118 & 755 & $846.5-1004.2$ \\
\hline
\end{tabular}

${ }^{\mathrm{ab}}$ Different letters indicate statistically significant difference(?) $(P<0.05) . \mathrm{G1}$, Desensibilize Nano P; G2, Desensibilize; G3, Desensibilize KF2\%; G4, Ultra EZ; G5, negative control.

protocols and the control group.

Regarding EDX analysis, G1 presented a significant increase in Ca-P peak concentration (atomic ratio: $\mathrm{Ca} / \mathrm{P}=2.20$ ) in comparison to the other groups, and presence of I, Yb, Mg, Si and S. G2 showed a reduction in Ca-P peak concentration $(\mathrm{Ca} / \mathrm{P}=1.87)$, presence of $\mathrm{Mg}, \mathrm{Si}$ and S similarly to $\mathrm{G} 1$; moreover, presence of $\mathrm{Sr}$ and $\mathrm{Cl}$.

G3 showed an increase in the Ca-P peak concentration, specially for $P$ (atomic ratio: $\mathrm{Ca} / \mathrm{P}=1.85$ ) in comparison to $\mathrm{G} 4$, and presence of $\mathrm{I}$, $\mathrm{Yb}$ and $\mathrm{Mg}$. G4 showed a reduction in the Ca-P peak concentration (atomic ratio: $\mathrm{Ca} / \mathrm{P}=1.88$ ), and presence of $\mathrm{I}, \mathrm{Yb}$ and $\mathrm{Mg}$. $\mathrm{G} 5$ (control group) showed a high Ca-P peak concentration (atomic ratio: $\mathrm{Ca}$ / $\mathrm{P}=2.21$ ), and lower concentration of $\mathrm{Mg}$, Si and S. Fig. 2 shows a representative image of energy-dispersive $\mathrm{x}$-ray analysis (EDX) of dentin surface after the desensitization protocols and the control group.

The bond strength of the adhesive system evaluated presented the means and standard deviation (MPa) from G1 to G5: $12.40 \pm 3.15$, $12.10 \pm 3.35,11.15 \pm 3.00,8.63 \pm 2.26$ and $8.06 \pm 1.38$. G1 and G2 presented higher adhesive system bond strength to cervical dentin than G4 and G5 $(P<0.05)$. No significant differences were found among G1, G2 and G3 and among G3, G4 and G5 (P > 0.05). As regards the fracture pattern evaluation, the images obtained by stereomicroscopy are shown in Fig. 3.The cohesive fracture pattern was frequently found in G1 (58.5\%), G2 (51.3\%) and G3 (43.8\%), adhesive fracture pattern, found frequently in G4 (47\%) and mixed fracture in G5 (39\%).

The hybrid layer formation presented the means and standard deviation $(\mu \mathrm{m})$ from $\mathrm{G} 1$ to $\mathrm{G} 5: 3.26 \pm 0.25,3.21 \pm 0.35,2.61 \pm 0.29$, $2.75 \pm 0.23$ and $2.69 \pm 0.68$. G1 and G2 was similar $(P>0.05)$, showing the highest hybrid layer formation values $(\mathrm{P}<0.05)$. G3 and G4 showed no differences from G5 $(P>0.05)$. Fig. 4 shows a representative image of formed hybrid layer (white arrows) after the desensitization protocols and control group.

\section{Discussion}

The hypothesis that the desensitizing agents would not interfere in the bond strength to cervical dentin and hybrid layer formation of 

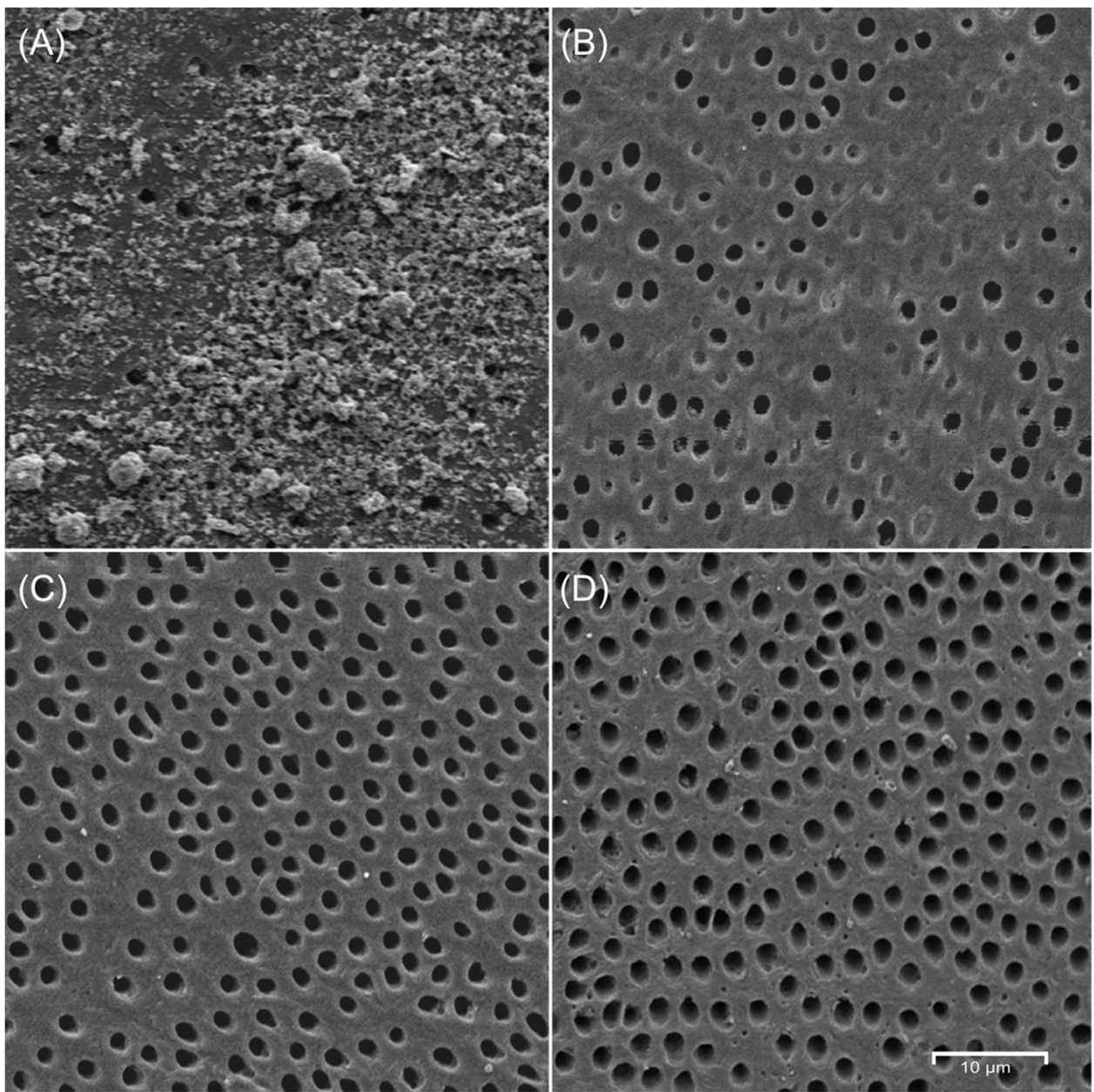

Fig. 1. Representative image of dentin surface after the desensitization protocols and the control group. (A) Desensibilize Nano P; (B) Desensibilize: (C) Desensibilize KF2\% and Ultra EZ; and (D) control. Scale $10 \mu \mathrm{m}$.

adhesive systems was rejected, because the desensitizers containing calcium phosphate nanoparticles (Nano P) or $10 \%$ strontium chloride (Desensibilize) increased the bond strength values and the hybrid layer formation of the adhesive system. Moreover, both $2 \%$ (Desensibilize $\mathrm{KF} 2 \%$ ) and $0.25 \%$ (Ultra EZ) sodium fluoride desensitizers presented the lowest bond strength values, only $2 \%$ sodium fluoride compound showed values similar to those of the other desensitizers.

The adhesion mechanism of recent adhesive systems is based on resin monomer infiltration into the demineralized dentin surface; after polymerization this creates a mixed substrate composed of collagen fibers and a resin material, called the hybrid layer [14]. For bonding, the smear layer needs to be removed by means of acid etching to remove the mineral content from superficial dentin zone, reducing the hydroxyapatite concentration and increasing the diameter of the dentinal tubules and dentin permeability [15].

EDX analysis showed different $\mathrm{Ca}$ and $\mathrm{P}$ ratios. Elements such as $\mathrm{Mg}$, $\mathrm{Ca}$ and $\mathrm{P}$ are normally detected on the dentin surface [16]. The groups presented similar chemical composition, except G2 that presented Sr and $\mathrm{Cl}$.

Strontium chloride creates strontium-apatite through the replacement of calcium by strontium that reduces dentin hydraulic conductance and blocks the tubules, in a similar way to that of acidic sodium fluoride [17]. This precipitate formation negatively interferes in the bond strength of total-etch adhesive systems even after dentin acid etching [18].

This present study concluded that the application of $10 \%$ strontium chloride favored the bond strength of the adhesive system to cervical dentin probably because the etch-and-rinse adhesive system was used as bond strategy. This can be explained because the etching and subsequent irrigation with distilled water possibly removed the precipitate formation on dentin, moreover the etch-and-rinse systems presents higher bonding property than self- etch adhesive systems [19-21].

Furthermore, the calcium phosphate nanoparticles (Desensibilize Nano P) desensitizer presented a similar effect. This material has been recommended for dentin hypersensitivity treatment and to prevent enamel erosion, by creating a protective film on dentin [5,22]. Its mechanism of action is possibly related to the ability to stabilize calcium and phosphate ions in an amorphous state in the dental structure, in a way similar to CPP-ACP [23]. The previous use of CPP-ACP does not interfere on bond strength of total-etch adhesive system to healthy or carious dentin, although no comparative studies using calcium phosphate nanoparticles desensitizers have previously been conducted [24,25].

The self-etch adhesive system partially demineralizes dentin and leaves the hydroxyapatite crystals around the collagen fibers. Its functional monomers (4-MET and 10-MDP) chemically interact with calcium ion from residual hydroxyapatite within the hybrid layer, promoting a dual mechanism of adhesion to dentin [26,27]. Similarly, although the present study used the etch-and-rinse (Scotchbond Multipurpose) adhesive system that contains hydroxyethyl methacrylate (HEMA) and copolymers from polyalkenoic acid, the hydroxyapatite residues from the composition of Nano P may have interacted with the monomers from this adhesive system, increasing the bond strength to dentin treated with the desensitizer. Therefore the bond strength after 

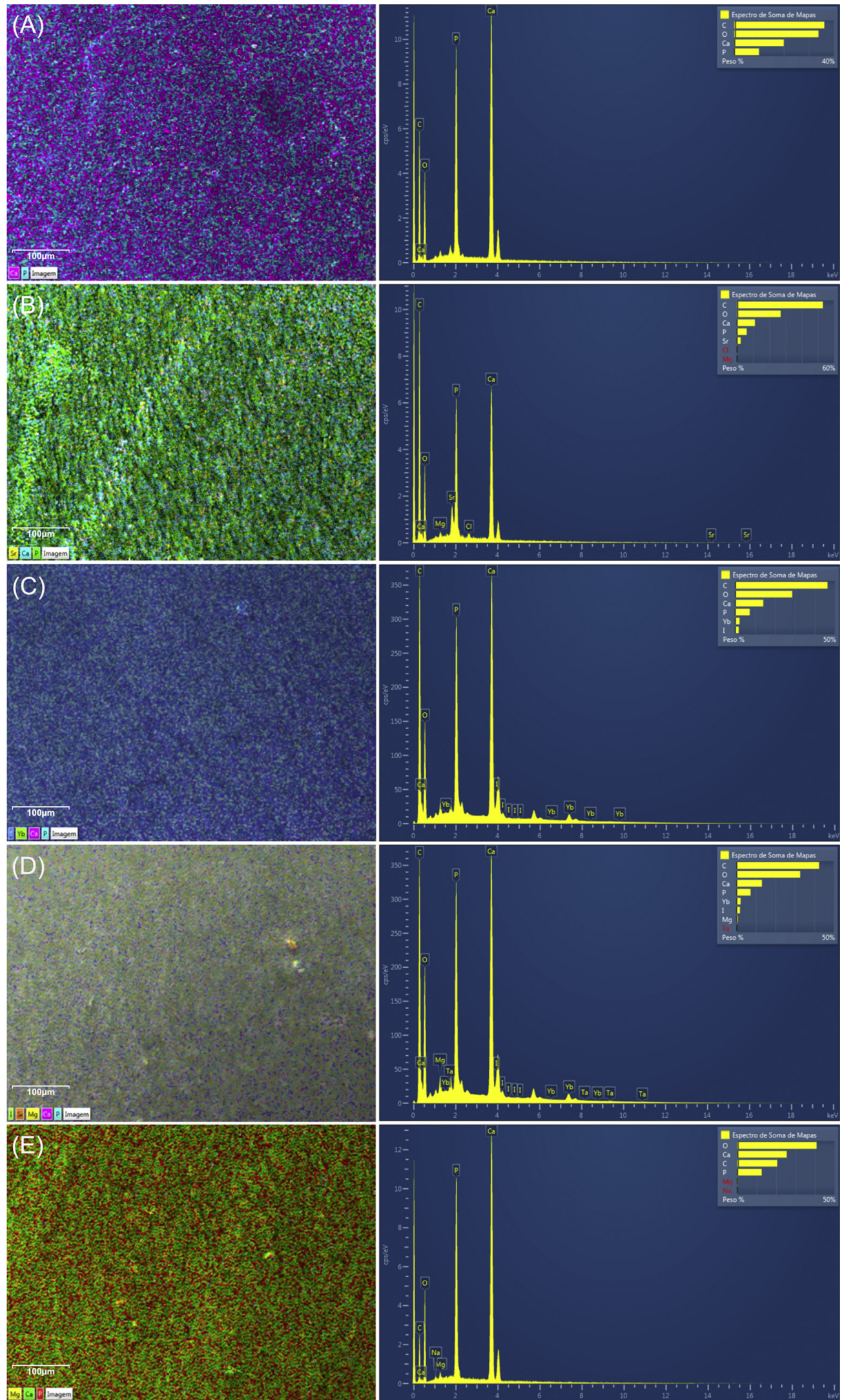

Fig. 2. Representative image of Energy-dispersive X-ray analysis (EDX) of dentin surface after the desensitization protocols and the control group. (A) Desensibilize Nano P; (B) Desensibilize: (C) Desensibilize KF2\%; (D) Ultra EZ; and (E) control. Scale $100 \mu \mathrm{m}$. 


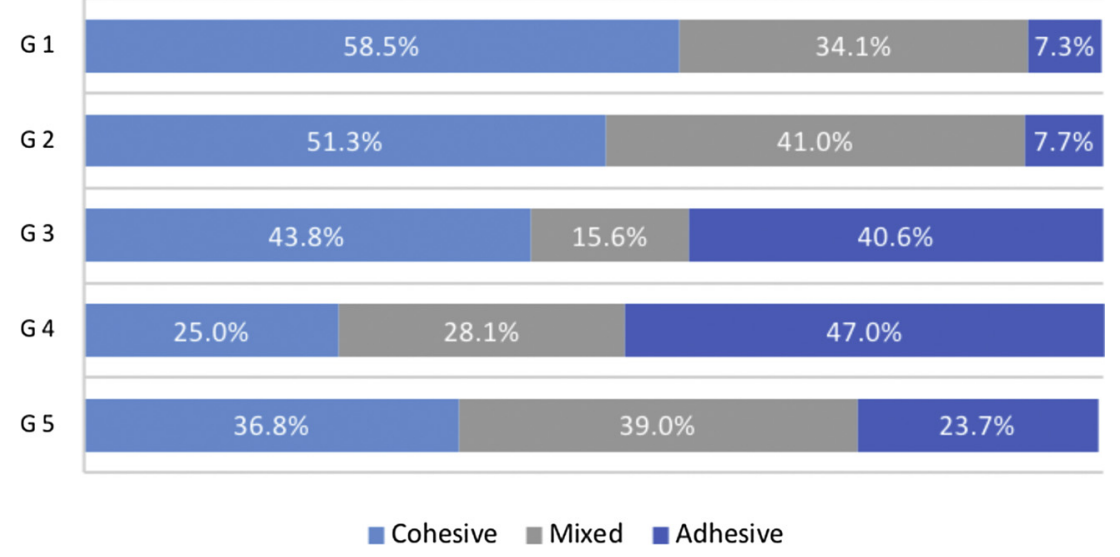

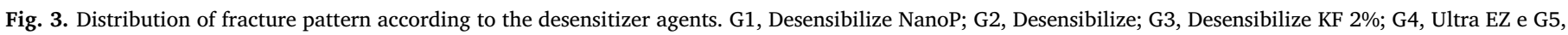
control.

the desensitizing agent possibly increased because a chemical-mechanical bonding was obtained, since there was a larger extent of hybrid layer formation in this group.

Fluoridated desensitizers react with calcium ions from dentinal fluid forming fluoride hydroxyapatite [28]. Studies have shown that the application of fluoride desensitizers did not affect the bond strength of self-etch adhesive systems to demineralized dentin, in agreement with the results found in the present study, although an etch-and-rinse adhesive system was used [29]. On the other hand, recent studies have shown a reduction in bond strength of adhesives to sound dentin after desensitization protocols, but this is inversely related to the fluoride concentration in the compound, because higher concentrations reduce the bond strength due to crystals precipitating on the dentin surface $[30,31]$. Moreover, bond strength was not affected in the groups containing fluoride as desensitizer due to the concentrations being relatively low: $2 \%$ in Desensibilize KF2\%, $0.25 \%$ in Ultra EZ and $0.9 \%$ in Nano P.

Thus, the chemical composition of dentin desensitizers can affect
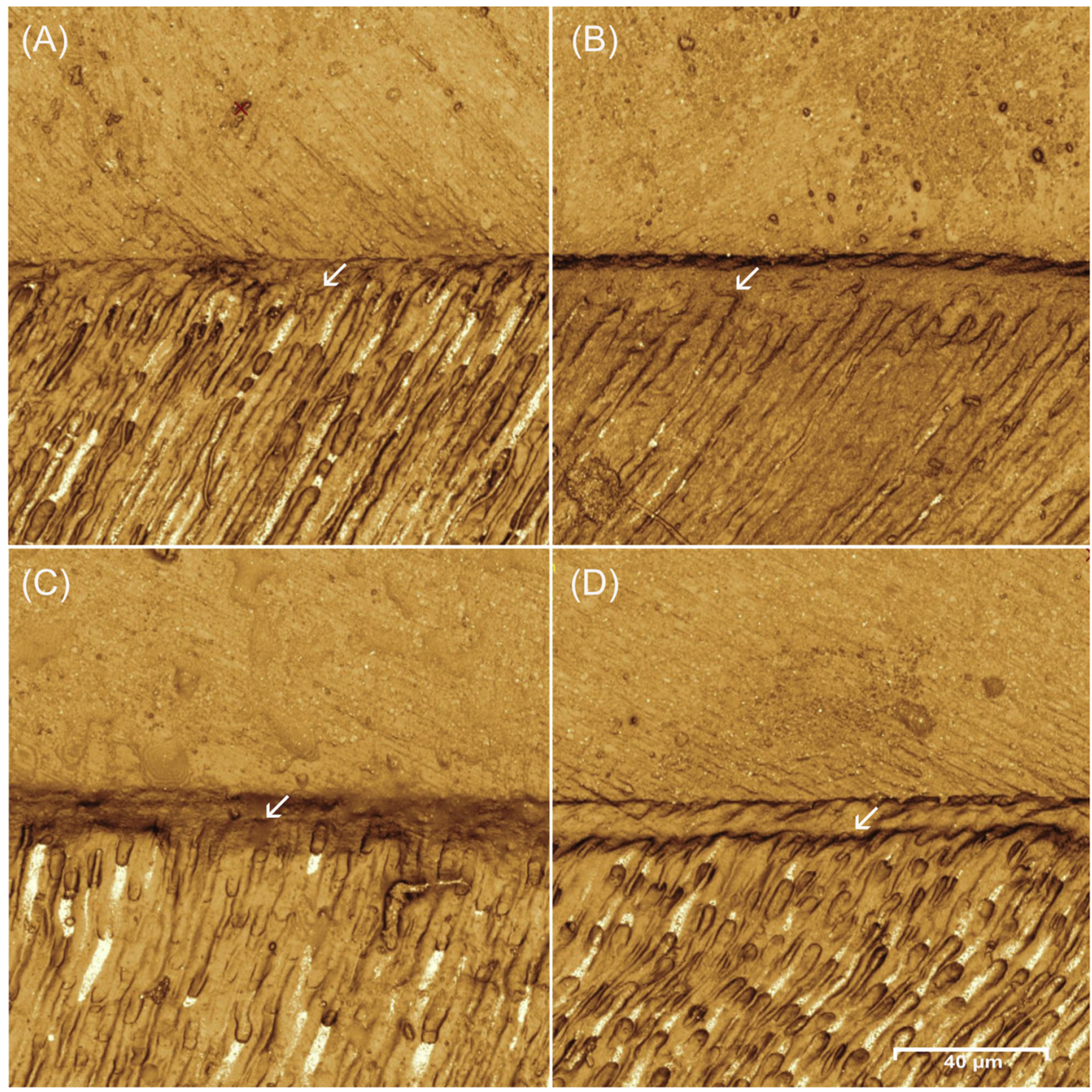

Fig. 4. Representative image of formed hybrid layer (white arrows) after the desensitization protocols and control group. (A) Desensibilize Nano P; (B) Desensibilize: (C) Desensibilize KF2\% and Ultra EZ; and (D) control. Scale $40 \mu \mathrm{m}$. 
the bond strength of adhesive systems to cervical dentin. Further studies should be conducted to evaluate the ideal sequence of application of desensitizers and the interactions between their compositions and different types of adhesive systems, and nanoleakage in the hybrid layer.

\section{Conclusions}

Within the limitation of this study, the authors concluded that the application of desensitizer containing calcium phosphate nanoparticles (Nano P) in 4 treatment sessions increased the bond strength of the etchand-rinse adhesive system and the hybrid layer formation in cervical dentin. It also provided higher level of dentinal tubule obliteration, however, it presented similar results to those of strontium chloride (Desensibilize) except when the precipitation of residues and open dentinal tubules counting were evaluated.

\section{Declaration of interests}

The authors declare that they have no conflict of interest.

\section{Acknowledgements}

The authors are indebted to PhD. Gisele Faria (Restorative Dentistry Department, Araraquara Dental School, São Paulo State University) and PhD Marco Hungaro Duarte (Dentistry, Endodontic and Dental Materials Department, Bauru Dental School, São Paulo University) for their excellent support.

\section{References}

[1] Canadian Advisory Board on Dentin Hypersensitivity, Consensus-based recommendations for the diagnosis and management of dentin hypersensitivity, J. Can. Den. Assoc. 69 (2003) 221-226.

[2] M. Addy, E. Urquhart, Dentine hypersensitivity: its prevalence, aetiology and clinical management, Dent. Update 19 (407-408) (1992) 410-412.

[3] P.A. Walters, Dentinal hypersensitivity: a review, J. Contemp. Dent. Pract. 6 (2005) 107-117.

[4] N.X. West, Dentine hypersensitivity: preventive and therapeutic approaches to treatment, Periodontology 2000 (48) (2008) 31-41.

[5] F.G. Carvalho, V.L. Brasil, T.J. Silva Filho, H.L. Carlo, R.L. Santos, B.A. Lima, Protective effect of calcium nanophosphate and CPP-ACP agents on enamel erosion, Braz. Oral Res. 27 (2013) 463-470.

[6] R. Orchardson, D.G. Gillam, Managing dentin hypersensitivity, J. Am. Dent. Assoc. 137 (2006) 990-998.

[7] N.P. Giassin, D.A. Apatzidou, K. Solomou, L.R. Mateo, F.S. Panagakos, A. Konstantinidis, Control of dentin/root sensitivity during non-surgical and surgical periodontal treatment, J. Clin. Periodontol. 43 (2016) 138-146.

[8] A. Davari, E. Ataei, H. Assarzadeh, Dentin hypersensitivity: etiology, diagnosis and treatment; A literature review, J. Dent. 14 (2013) 136-145.

[9] A.O. Olusile, C.T. Bamise, A.O. Oginni, O.O. Dosumu, Short-term clinical evaluation of four desensitizing agents, J. Contemp. Dent. Pract. 9 (2008) 22-29.

[10] T. Pamir, H. Dalgar, B. Onal, Clinical evaluation of three desensitizing agents in relieving dentin hypersensitivity, Oper. Dent. 32 (2007) 544-548.

[11] Sda S. Freitas, L.L. Sousa, J.M. Moita Neto, R.F. Mendes, R.R. Prado, Dentin hypersensitivity treatment of non-carious cervical lesions - a single-blind, split-mouth study, Braz. Oral Res. 29 (2015) 1-6.

[12] W. Escalante-Otárola, G. Castro-Núñez, K. Jordão-Basso, S.L. Lima, Bandeca M.C. KugaMC, Treatment protocol for dentin hypersensitivity, World J. Dent. 8 (2017) 1-4.

[13] M.C. Kuga, M.V. Só, N.B. De Faria Jr., K.C. Keine, G. Faria, S. Fabricio, M.A. Matsumoto, Persistence of resinous cement residues in dentin treated with different chemical removal protocols, Microsc. Res. Tech. 75 (2012) 982-985.

[14] N. Nakabayashi, K. Kojima, E. Masuhara, The promotion of adhesion by the infiltration of monomers into tooth substrates, J. Biomed. Mater. Res. 16 (1982) 265-273.

[15] J.I. Rosales-Leal, R. Osorio, J.A. Holgado-Terriza, M.A. Cabrerizo-Vílchez, M. Toledano, Dentin wetting by four adhesive systems, Dent. Mater. 17 (2001) $526-532$.

[16] G. Eliades, M. Mantzourani, R. Labella, B. Mutti, D. Sharma, Interactions of dentine desensitisers with human dentine: morphology and composition, J. Dent. 41 (2013) S28-S39.

[17] A.F. Paes Leme, J.C. dos Santos, M. Giannini, R.S. Wada, Occlusion of dentin tubules by desensitizing agents, Am. J. Dent. 17 (2004) 368-372.

[18] F.A. Maeda, A.P. Guedes, A. Catelan, S. Pavan, A.L. Briso, R.H. Sundfeld, P.H. dos Santos, Influence of desensitizing agents on the microshear bond strength of adhesive systems to dentin, Acta odontológica Latinoamericana 22 (2009) 41-45.

[19] E. Can Say, M. Nakajima, P. Senawongse, M. Soyman, F. Ozer, M. Ogata, J. Tagami, Microtensile bond strength of a filled vs unfilled adhesive to dentin using self-etch and total-etch technique, J. Dent. 34 (2006) 283-291.

[20] D. Saraç, S. Külünk, Y.S. Saraç, O. Karakas, Effect of fluoride-containing desensitizing agents on the bond strength of resin-based cements to dentin, J. Appl. Oral Sci. 17 (2009) 495-500.

[21] D. Saraç, B. Bulucu, Y.S. Saraç, S. Kulunk, The effect of dentin-cleaning agents on resin cement bond strength to dentin, J. Am. Dent. Assoc. 139 (2008) 751-758.

[22] I.C. Medeiros, V.L. Brasil, H.L. Carlo, R.L. Santos, B.A. De Lima, F.G. De Carvalho, In vitro effect of calcium nanophosphate and high-concentrated fluoride agents on enamel erosion: an AFM study, Int. J. Paediatr. Dent. 24 (2014) 168-174.

[23] S. Madhavan, M. Nayak, A. Shenoy, R. Shetty, K. Prasad, Dentinal hypersensitivity: a comparative clinical evaluation of CPP-ACP F, sodium fluoride, propolis, and placebo, J. Conserv. Dent. 15 (2012) 315-318.

[24] M. Bahari, S. Savadi Oskoee, S. Kimyai, F. Pouralibaba, F. Farhadi, M. Norouzi, Effect of casein phosphopeptide-amorphous calcium phosphate treatment on microtensile bond strength to carious affected dentin using two adhesive strategies, J. Dent. Res., Dent. Clin., Dent. Prospect. 8 (2014) 141-147.

[25] M. Doozandeh, M. Firouzmandi, M. Mirmohammadi, The simultaneous effect of extended etching time and casein phosphopeptide-amorphous calcium phosphate containing paste application on shear bond strength of etch-and-rinse adhesive to caries-affected dentin, J. Contemp. Dent. Pract. 16 (2015) 794-799.

[26] B. Van Meerbeek, K. Yoshihara, Y. Yoshida, A. Mine, J. De Munck, K.L. Van Landuyt, State of the art of self-etch adhesives, Dent. Mater. 27 (2011) 17-28.

[27] Y. Yoshida, K. Nagakane, R. Fukuda, Y. Nakayama, M. Okazaki, H. Shintani, S. Inoue, Y. Tagawa, K. Suzuki, J. De Munck, B. Van Meerbeek, Comparative study on adhesive performance of functional monomers, J. Dent. Res. 83 (2004) 454-458.

[28] C. Oberg, M.T. Pochapski, P.V. Farago, C.J. Granado, G.L. Pilatti, F.A. Santos, Evaluation of desensitizing agents on dentin permeability and dentinal tubule occlusion: an in vitro study, Gen. Dent. 57 (2009) 496-501.

[29] A. Sengun, A.E. Koyuturk, Y. Sener, F. Ozer, Effect of desensitizers on the bond strength of a self-etching adhesive system to caries-affected dentin on the gingival wall, Oper. Dent. 30 (2005) 430-435.

[30] S. Külünk, D. Sarac, T. Külüink, O. Karakas, The effects of different desensitizing agents on the shear bond strength of adhesive resin cement to dentin, J. Esthet. Restor. Dent. 23 (2011) 380-387.

[31] K. Soeno, Y. Taira, H. Matsumura, M. Atsuta, Effect of desensitizers on bond strength of adhesive luting agents to dentin, J. Oral Rehabil. 28 (2001) 1122-1128. 